\title{
고속도로 $\mathrm{CCTV}$ 를 이용한 광역시정정보시스템 구축과 활용 방안에 대한 연구
}

이 광* 김봉근

\section{Study on Development and Utilization of Wide Area Visibility Information System Using CCTV on the Highway}

\author{
Gwang Lee* $\cdot$ Bong-Keun Kim ${ }^{* *}$ \\ 요 약
}

최근 조사에 따르면 안개로 인한 교통사고 사망자 수가 비나 눈에 의한 교통사고 사망자 수보다 많은 것으 로 나타났다. 따라서 안개 발생 시 정확한 시정을 측정할 수 있는 방법과 측정된 시정을 운전자에게 전달하여 교통사고의 발생을 방지하는 방안이 요구되고 있다. 우리는 고속도로에 설치된 CCTV 카메라를 활용해 실시 간으로 도로시정을 측정할 수 있는 시스템을 개발하였다. 본 논문에서는 우리가 개발한 실시간 도로시정측정 시스템을 활용해 모든 고속도로의 시정을 측정할 수 있는 광역시정정보시스템의 구축 방안을 제안한다. 제안 된 방법은 고비용의 안개선서가 아닌 기존 $\mathrm{CCTV}$ 영상을 사용해 시정을 측정하므로 설치와 운용비용을 획기 적으로 줄일 수 있으며, 측정된 모든 고속도로의 시정정보는 다양한 방법과 목적으로 활용될 것으로 기대한다.

\section{ABSTRACT}

Recent researches show that the traffic fatality rate in fog is higher than that in rain and snow. In that sense, methods to measure visibility accurately and to notify the measured visibility information to drivers are required. We thus developed a system for measuring the road visibility in realtime by employing CCTV cameras. In this paper, we also propose a wide-area visibility information system through measuring the visibility of every highway by using the developed system. The proposed wide-area visibility information system uses the video clips from the CCTV camera instead of the output from the expensive fog sensor. Hence, we expect that it can reduce the cost of installation and operation dramatically and the measured visibility information has a number of applications.

\section{키워드}

CCTV, For Warning System, ITS, Visibility

안개, 시정정보, 안개센서, 고속도로

\section{I. 서 론}

2013년 도로교통공단의 조사에 따르면 2012년 한 해 동안 사망자가 발생한 교통사고 5,165 건을 분석한
결과 눈이나 비가 오는 날보다 안개가 발생한 날의 교통사고 사망자 수가 가장 높은 것으로 조사되었다. 사망 사고율을 전체 평균 사망 사고율로 나눈 상대 사망 사고율 수치가 4.25 로 나타났으며, 눈과 비가 오

\footnotetext{
* 한국교통대학교 소프트웨어학과(gwang@ut.ac.kr)

** 교신저자(corresponding author) : 한국교통대학교 소프트웨어학과(bkkim@ut.ac.kr)

접수일자 : 2014. 04. 18

심사(수정)일자 : 2014. 05. 23
}

게재확정일자 : 2014. 06. 16 
는 날의 상대사망 사고율인 0.95 와 1.18 보다 높은 것 으로 조사되어 안개로 인한 교통사고가 가장 많은 사 망자를 발생시키는 것으로 조사되었다[1].

안개로 인한 대형 교통사고의 대표적인 예는 2006 년 10월 서해대교에서 발생한 29중 추돌 사고이며, 이 사고를 계기로 관련기관에서는 도로안전시설물 확충, 도로 이용자에 대한 잠재적 위험성 홍보 및 규제, 도 로운영 관리 능력 강화 등을 포함한 다양한 안개 관 련 대책들을 마련하여 시행 중에 있다.

하지만 우리나라 국토의 대부분이 산지이고 안개발 생 지역이 국소적이며 광범위하게 존재하고 있기 때 문에 안개로 인한 교통사고 발생을 방지하기 위한 교 통안전시설들은 많은 효과를 거두지 못하고 있으므로 이에 대한 적절한 대비가 요구되고 있다. 우리는 안개 센서가 아닌 고속도로에 설치된 $\mathrm{CCTV}$ 영상을 활용 해 시정거리를 실시간으로 측정할 수 있는 실시간 도 로시정측정 시스템을 개발하였다.

본 논문에서는 실시간 도로시정측정 시스템을 활용 해 고속도로 전 구간의 시정을 측정할 수 있는 광역 시정정보시스템의 구축 방안을 제안하고자 한다. 또한 광역시정정보시스템의 경제성을 분석하며 활용방안을 제시하고자 한다. 제안된 광역시정정보시스템은 기존 에 설치되어 있는 $\mathrm{CCTV}$ 카메라 영상을 사용하므로 현재 안개자동경보시스템에서 시정측정을 위한 핵심 장치인 안개센서(fog sensor) 대비 설치와 운용비용을 획기적으로 감소시킬 수 있으며, 모든 고속도로의 시 정정보를 다양한 목적으로 활용할 수 있다.

\section{II. 안개와 고속도로 안개 발생현황}

\section{1. 안개의 분류와 기준}

수증기가 응결핵을 중심으로 응결하면 구름이나 안 개가 되는데, 이때 지표면에 접하고 있고 시정이 $1 \mathrm{Km}$ 이하일 때를 안개라고 정의한다.

안개는 발생의 원인에 따라 복사안개, 역전안개, 이 류안개, 활승안개, 증발안개, 전선안개 등으로 분류된 다. 복사안개는 복사 냉각으로 인해 지표의 온도가 공 기의 온도보다 낮을 때 발생되며, 이류안개는 따뜻하 고 습한 공기가 차고 습한 공기 위에 형성될 때 발생 된다. 활승안개는 습한 공기가 산비탈을 따라 상승하
고 응결되어 발생되며, 역전안개는 역전층 아래의 층 운 등이 지표면으로 도달할 때 발생된다. 증발안개는 찬 공기가 따뜻한 수면이나 지면 위를 지날 때 증발 된 수증기가 포화되고 응결되어 발생되며, 전선안개는 온난전선이나 한랭전선 부근의 따뜻한 공기가 상승할 때 발생된다. 시정에 따른 안개의 국제적 분류 기준은 표 1 과 같다[2].

표 1. 시정에 대한 안개의 국제적 분류 Table 1. International classifications of fogs by visibility

\begin{tabular}{c|c}
\hline Visibility & Definition \\
\hline \hline less than $40 \mathrm{~m}$ & dense fog \\
\hline $40 \sim 200 \mathrm{~m}$ & thick fog \\
\hline $200 \sim 1,000 \mathrm{~m}$ & fog \\
\hline $1 \sim 2 \mathrm{Km}$ & mist \\
\hline $2 \sim 4 \mathrm{Km}$ & haze \\
\hline $4 \sim 10 \mathrm{Km}$ & poor visibility \\
\hline $10 \sim 40 \mathrm{Km}$ & good visibility \\
\hline more than $40 \mathrm{Km}$ & excellent visibility \\
\hline
\end{tabular}

표 1 에서와 같이 안개의 국제적 분류에 따르면 안 개는 시정이 $1 \mathrm{~km}$ 이하일 때를 말하며, $200 ~ 1,000 \mathrm{~m}$ 를 안개(fog), $40 \sim 200 \mathrm{~m}$ 를 짙은 안개(thick fog), $40 \mathrm{~m}$ 이하를 농밀한 안개(dense fog)로 정의하고 있다.

\section{2. 우리나라의 안개발생 현황}

우리나라 고속도로의 안개발생 현황은 그림 1 과 같 다. 고속도로에서 안개가 발생하는 일수가 30 일 미만 인 지점이 94 개소, 30 일 50 일이 발생하는 지점이 51 개소, 51 일 100 일인 지점이 26 개소이고 100 일이 넘 는 지점도 6 개소에 이르는 것으로 나타나 있다.

경부선과 중부선에 안개발생 지역이 다수 분포되어 있으며, 특히 중부선의 경우 안개발생 일수가 50 일 이 상인 지점이 17 개소에 이르고 있다. 또한 안개발생이 100 일 이상인 지점이 영동선과 중앙선은 물론 해안에 가까운 서해안선과 88선에 다수 존재하고 있다[2]. 


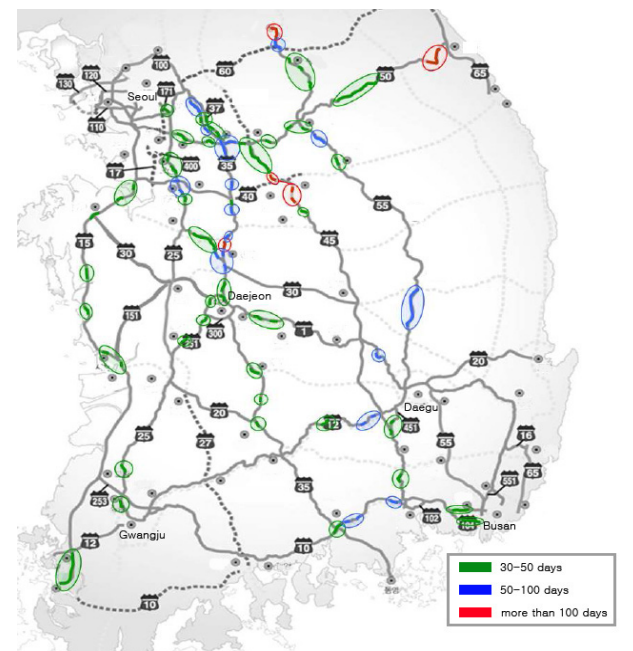

그림 1. 고속도로의 안개 발생 현황

Fig. 1 The occurrence of fogs on the highway

\section{III. 실시간 도로시정측정 시스템}

최근 카메라는 보안 감시용, 산업용, 차량의 화상 감시용 또는 교통관리 등의 다양하고도 광범위한 용 도로 사용되고 있으며, CCTV 기술이 IP 네트워크와 연결하여 그 사용이 갈수록 증대되고 있다[3-5].

실시간 도로시정측정 시스템은 $\mathrm{CCTV}$ 카메라 영상 에서 도로상에 통행중인 차량의 이동영역이 시정에 따라 달라진다는 점에 착안하여 차량의 이동영역을 추출하고 이를 이용하여 가시거리를 계산한다. 그림 2 는 도로가 수평일 경우 영상과 거리 사이의 관계를 나타낸 것이다.

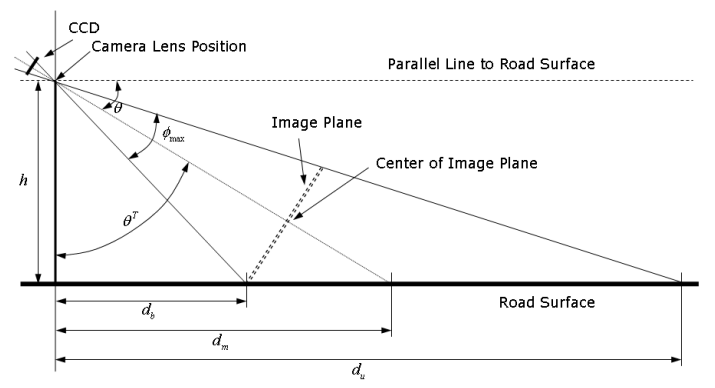

그림 2. 도로가 수평일 경우 영상과 거리의 관계

Fig. 2 The relationship between the image and the distance, if the road surface is horizontal
도로의 표면이 수평인 곳에 카메라가 일정높이(h) 에 설치되어 있고, 카메라가 설치된 각도 $(\theta)$ 와 카메라 의 높이 $C_{h}$ 를 사전에 알 수 있다면, 카메라 뷰앵글의 최대값 $\Phi_{\max }$ 는 카메라의 초점거리(focal length) $f$ 를 이용하여 식(1)과 같이 계산될 수 있고, 이미지상의 최하단, 중간, 최상단까지의 거리는 식(2)부터 식(4)와 같이 계산될 수 있다[6].

$\Phi_{\max }=\tan ^{-1}\left(C_{h} / f\right)$

$d_{b}=\tan \left(\theta^{T}-\frac{\Phi_{\max }}{2}\right) \cdot h$

$d_{m}=\tan \left(\theta^{T}\right) \cdot h$

$d_{u}=\tan \left(\theta^{T}+\frac{\Phi_{\max }}{2}\right) \cdot h$

일반적으로 CCTV 카메라 영상에서의 도로는 수평 인 경우가 거의 없고, 2차원 영상에서 특정 목표물까 지의 거리를 정밀하게 계산하기는 어렵다. 하지만 이 장치가 안개 발생 시 시정거리를 측정하기 위해 사용 되는 것을 고려할 때 정밀한 거리 계산을 필요로 하 지 않으며, 일반적으로 영상의 하단에서 상단까지의 거리 변화는 도로의 경사도에 따라 다소 차이는 있지 만 지수적으로 증가한다는 사실이 이미 연구되어 있 으므로[7] 시정거리는 측정될 수 있다.

따라서 영상으로부터 차량의 이동영역을 추출하여 움직임을 확인할 수 있는 최대거리인 가시선(visible line) 즉, 영상에서 차량의 이동이 확인되는 영역의 상 단을 나타내는 수평선을 정확히 검출할 수 있고, 가시 선과 거리에 대한 함수를 알 수 있다면 시정거리는 측정될 수 있다. 즉, $k$ 번째 영상 $I_{k}$ 의 가시선 높이 $h_{I_{k}}$ 와 시정 $v_{I_{k}}$ 간 상관관계를 나타내는 함수 $M$ 을 알고 있다면 시정은 식 (5)와 같이 계산될 수 있다[7].

$v_{I_{k}}=M\left(h_{I_{k}}\right)$

그림 3 은 목적함수와 가시선을 이용한 시정거리의 측정방법을 나타낸다. 


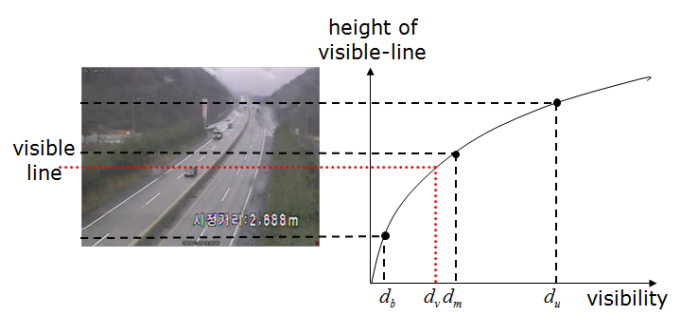

그림 3. 목적함수와 가시선을 사용한 시정측정

Fig. 3 Visibility measurement using the objective function(the exponential function) and a visible-line

가시선의 높이와 시정간의 함수를 도로모델(road model)이라고 정의할 때, 실시간 도로시정측정 시스 템은 그림 4 와 같다.

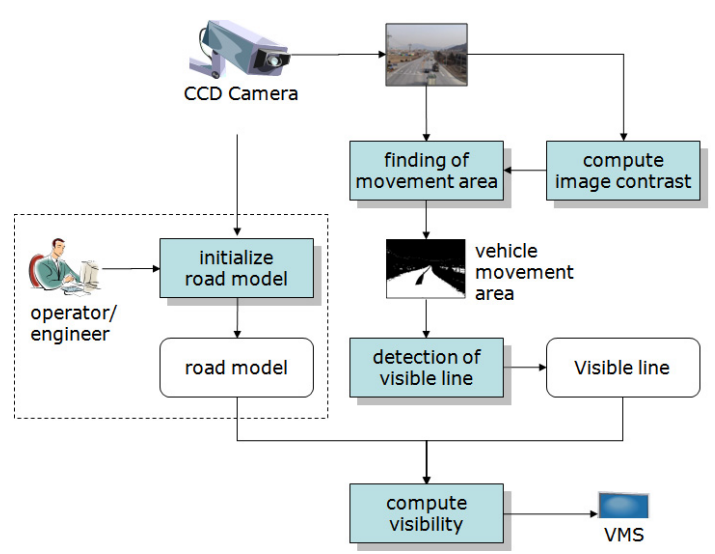

그림 4. CCTV를 이용한 도로시정측정 시스템

Fig. 4 Road visibility measurement system using CCTV

$\mathrm{CCTV}$ 를 이용한 실시간 도로시정측정 시스템은 크 게 초기화 단계와 운영 단계로 나뉜다.

초기화 단계는 운영자가 도로모델을 구축하는 단계 로 도로 이미지를 포함하는 하단, 중단, 상단의 영역 에 대한 기준선을 지정하고 운영자가 실측을 통해 각 기준선과 카메라의 거리를 지정한 다음 이를 목적함 수의 파라미터로 결정한다. 이는 도로시정측정 시스템 설치 시에 한 번만 수행하면 된다[8].

그림 5는 도로모델의 파라미터를 결정하는 것을 나 타낸다. 운영단계는 차량의 이동영역으로부터 얻어진 가시선과 도로모델을 이용하여 시정을 측정하고 그 결과를 표출하는 단계이다.

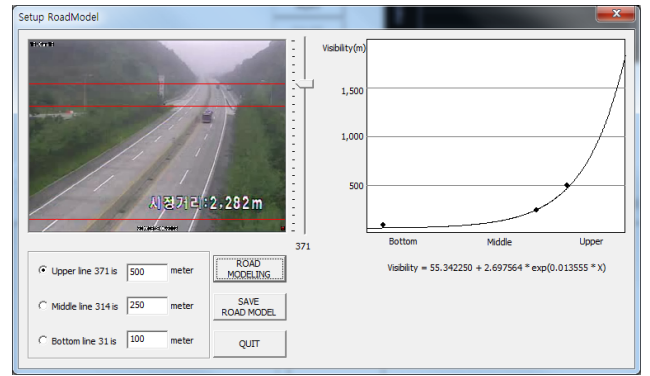

그림 5. 도로모델의 파라미터 결정

Fig. 5 Parameter decision of road model

그림 6 은 실시간 시정측정 시스템 구현 결과를 나 타낸 것이다.

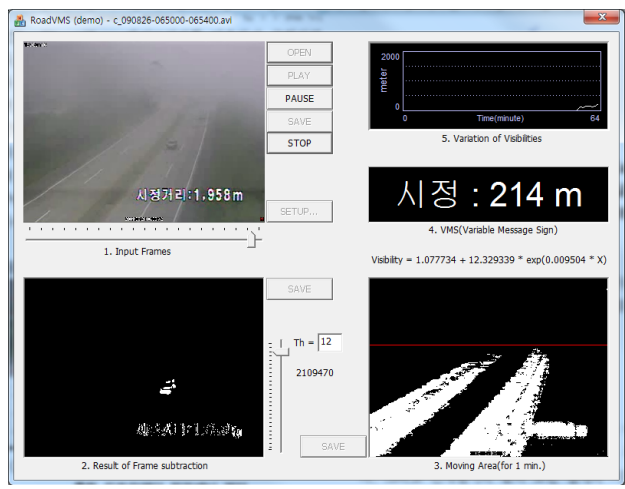

(a) Implemental result when fog is occurred

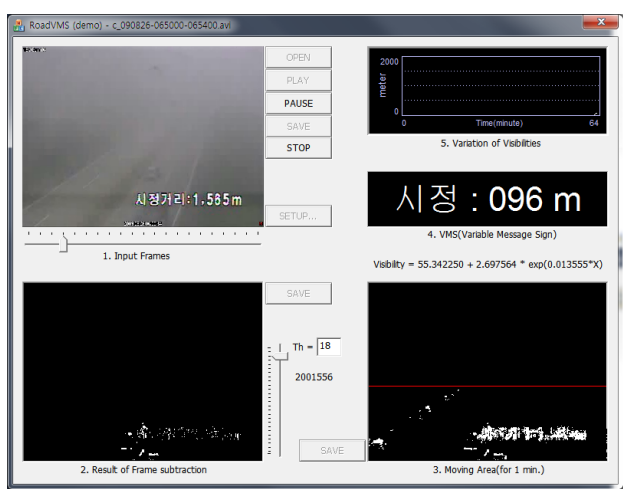

(b) Implemental result when thick fog is occurred 그림 6. 실시간 도로시정측정 시스템의 구현결과 Fig. 6 Implemental result of realtime road visibility measurement system 
그림 (a)는 시정거리가 200 1,000의 범위에 속하는 안개가 발생된 상황의 실험결과는 나타내며, 그림 (b) 는 시정거리가 20 200m 범위에 속하는 짙은 안개가 발생된 상황의 실험 결과를 나타낸다.

\section{IV. 광역시정정보시스템 구축과 활용 방안}

\section{1. 구축의 필요성과 방안}

현재 지능형교통시스템과 연계하여 운영되고 있는 교통안전관리시스템에서 안개발생 지역의 시정을 측 정하기 위한 핵심장치로 안개센서를 사용하고 있다. 안개센서와 같이 광학기기를 사용해 시정을 측정하는 방법은 안개의 밀도 변화가 급격하게 발생할 경우 시 정의 정확성을 기대하기 어려우며, 운전자의 시정감각 과도 차이를 보일 수 있다[9]. 그림 6의 좌측상단 $1,958 \mathrm{~m}$ 는 안개센서가 측정한 시정을 나타내며, 우측 상단의 $214 \mathrm{~m}$ 는 실시간 도로시정측정 시스템이 측정 한 시정을 나타낸다. 이는 안개밀도의 불균일성으로 인한 안개센서의 문제점을 보여주는 단편적인 예라 할 수 있다. 하지만 특정 근접 거리에 존재하는 인개 입자에 대한 밀도를 측정하는 안개센서와는 달리 인 간의 시정감각과 유사한 $\mathrm{CCTV}$ 영상으로부터 차량의 이동영역을 추출하여 이동이 확인되는 영역의 상단을 나타내는 수평선을 정확히 검출함으로써 시정거리를 측정하는 우리의 방법이 광학기기를 사용하는 측정 방법의 단점을 보완할 수 있다고 판단된다.

카메라를 이용해 안개의 발생 시 시정거리를 측정 하여 운전자에게 전달하는 연구[6]도 이루어졌지만 대 부분의 안개경보시스템은 고가의 안개센서를 사용하 고 있다. 운전자의 시정감각과 유사한 카메라 영상을 이용하는 방법은 카메라와는 별도의 표지를 필요로 하거나 ROI를 기반으로 하고 있어 설치가 어렵고 비 용이 많이 소요되며 기존 고속도로에 설치된 $\mathrm{CCTV}$ 를 사용하기 어렵다는 단점을 가진다. 또한 안개센서 를 사용하고 있는 우리나라의 안개경보시스템은 안개 다발 지역에 국부적으로 설치되어 운영되고 있으며, 고속도로 전 구간의 안개 발생에 따른 시정거리를 측 정하고 통합 관리하는 시스템은 현재 부재한 상태이 다. 따라서 고속도로 전 구간에 대해 안개의 발생에 따른 시정거리를 측정하여 통합운영 관리가 가능한
광역시정정보시스템이 요구되며, 제안된 시스템은 안 개로 인한 교통사고의 예방은 물론 측정된 시정정보 는 다양한 방법과 목적으로 사용될 수 있으리라 판단 된다.

제안된 광역시정정보시스템은 우리가 개발한 $\mathrm{CCTV}$ 영상을 활용하는 실시간 도로시정측정 시스템 을 기반으로 한다. 앞서 언급했듯이 카메라의 영상은 인간의 시정 감각과 유사하므로 안개센서보다 비교적 정확한 시정정보를 운전자에게 제공할 수 있다. 실시 간 도로시정측정 시스템은 측정가능 거리가 $\mathrm{CCTV}$ 영상에 나타나는 최대 거리로 한정되므로 도로환경에 만 사용할 수 있다는 단점이 있지만 실제 도로를 주 행하는 운전자에게는 안개로 판단되는 거리인 약 $1 \mathrm{~km}$ 이내의 시정만이 필요하다는 점에서 실제 적용하 는 데에는 문제가 없는 것으로 판단된다. 그림 7은 실 시간 도로시정측정 시스템을 활용하는 광역시정정보 시스템의 구성을 나타낸다.

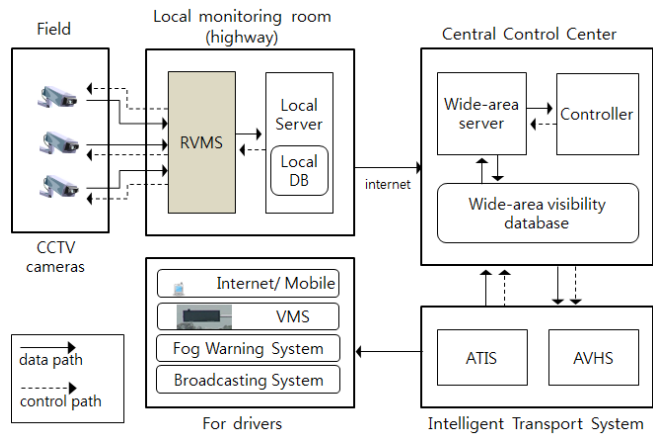

그림 7. 광역시정정보시스템의 구성

Fig. 7 Construction of wide-area visibility information system

고속도로의 각 지역별 상황실에는 실시간 도로시정 시스템과 지역서버 및 데이터베이스를 구축하고 중앙 관제 센터에는 광역서버와 데이터베이스를 구축한다. 고속도로의 $\mathrm{CCTV}$ 의 영상들은 각 지역의 고속도로 상황실에 설치된 실시간 도로시정측정 시스템으로 전 송되어 시정거리가 산출된다. 산출된 정보는 지역 데 이터베이스에 유지됨과 동시에 중앙관제센터의 광역 서버로 전송되어 전국 고속도로의 안개 발생 현황 및 시정거리가 산출된다. 광역서버는 실시간으로 측정된 시정거리를 지능형교통시스템과 연계하여 기존 도로 
교통 시설이나 각종 장비를 사용해 운전자에게 전달 하게 된다.

\section{2. 경제성 분석 및 활용방안}

광역시정정보시스템의 시정측정 장치인 실시간 도 로시정측정 시스템은 기존에 고속도로에 설치된 CCTV와 연결해 사용되며, 그림 8은 실시간 도로시정 측정 시스템과 기존 $\mathrm{CCTV}$ 와의 연결 방법을 나타낸 것이다.

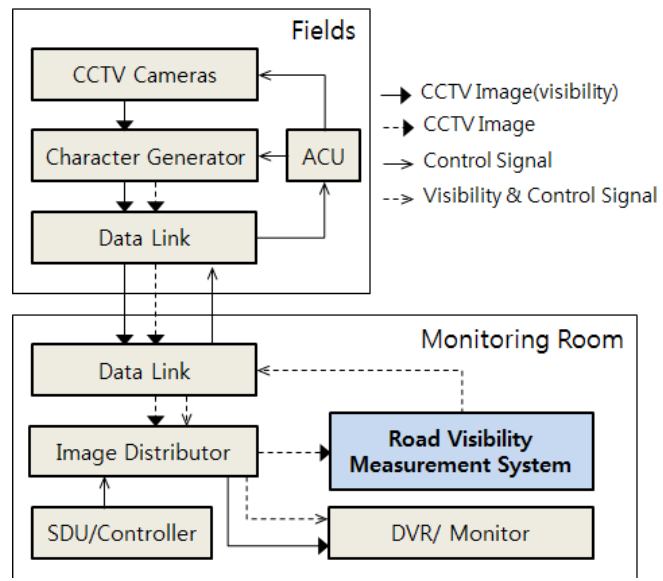

그림 8. 도로시정측정 시스템과 기존 CCTV의 연결

Fig. 8 Connection between the road visibility measurement system and the existing CCTV

그림 8에서와 같이 실시간 시정측정 시스템(RVMS) 은 CCTV 영상출력 단자의 영상 분배기에 연결만 하면 되므로 기존의 CCTV와 쉽게 연결하여 활용될 수 있 다. 따라서 광역시정정보시스템에서는 시정 측정을 위 한 핵심장치로 기존의 CCTV 영상을 사용하므로 비용 을 크게 감소시킬 수 있다.

실시간 도로시정측정 시스템의 제작비용은 부속장치 와 모듈 개발비를 포함해 약 300 만원 정도이며, 기존 안개센서를 사용하는 시스템이 약 2,000 3,000만원 정 도인 점을 감안하면 매우 저렴한 비용으로 구축할 수 있다. 현재 고속도로에는 2,000개 이상의 CCTV 시스템 이 운영되고 있다. 만일 고속도로에 설치된 $\mathrm{CCTV}$ 카 메라가 2,000개이고 고속도로의 모든 곳에 안개센서를 설치한다면 약 400억원 이상의 비용이 소요되지만 실 시간 도로시정측정 시스템을 사용하는 경우에는 약 60
억원 정도만 소모되므로 저렴한 비용으로 고속도로 전 구간의 시정을 측정할 수 있으며, 실시간 도로시정측정 시스템을 사용하는 광역시정정보시스템 역시 저렴한 비용으로 구축할 수 있다.

광역시정정보시스템은 지능형교통시스템(ITS)의 첨 단 교통정보 시스템(ATIS)및 첨단 차량 및 도로 시 스템(AVHS) 등과 연계하여 안개로 인한 교통사고를 미연에 방지하고 도로교통 안전시설물에 대한 관리와 보완에 활용될 수 있다. 지능형교통시스템과 연계하여 고속도로 전 구간에 대한 안개 발생 및 변화 상황을 파악하고 시정정보를 도로전광판(VMS)과 같은 도로 교통 안전시설물을 통해 운전자에게 전달하거나 공중 파 방송국과 이동통신 사업자에게 전달하여 공중파 방송과 웹서비스는 물론 와이브로, LTE 및 스마트폰 어플리케에션 등의 모바일 기기를 통해 실시간으로 운전자에게 제공함으로써 안전 운전을 유도하고 안개 로 인한 교통사고의 발생을 미연에 방지하여 인적, 사 회적 비용의 손실을 절감할 수 있다.

또한 측정된 시정정보를 광역시정데이터베이스에 저장하고 각종 기상관측 시스템과 연계함으로써 안개 발생 예측, 안개로 인한 재해의 예방 및 각종 기상관 련 연구 등 다양한 목적으로 활용될 수 있다.

\section{V. 결 론}

안개로 인한 교통사고 사망자의 수는 눈이나 비가 올 때보다 훨씬 많은 것으로 조사되었으며, 이는 안개 로 인한 교통사고의 방지를 위한 많은 노력이 필요하 다는 것을 반증하고 있다.

본 논문은 우리가 개발한 실시간 도로시정측정 시 스템을 활용해 광역시정정보시스템의 구축 방법을 제 안하였다. 기존 $\mathrm{CCTV}$ 의 영상을 활용하는 광역시정정 보시스템은 안개센서에 대비해 매우 저렴한 비용으로 시정을 측정할 수 있으며, 지능형교통시스템과 연계하 여 안개 발생 시 정확한 시정정보를 다양한 방법으로 운전자에게 전달해 안개로 인한 교통사고를 예방할 수 있으리라 판단된다. 또한 광역시정정보시스템의 구 축으로 수집되는 시정정보는 안개발생의 예측이나 안 개로 인한 재해의 예방 및 각종 기상관련 연구 등의 다양한 목적으로 활용될 수 있을 것으로 기대된다. 
현재 우리는 $\mathrm{HD} \mathrm{CCTV} \mathrm{카메라} \mathrm{영상을} \mathrm{시정측정}$ 장치에 적용하는 방법과 광역시정정보시스템 구성을 위해 실시간 도로시정측정 시스템을 지능형교통시스 템에 적용하여 상용화하는 방안을 연구하고 있다.

\section{감사의 글}

이 논문은 2013년도 한국교통대학교 교내학술연구비

의 지원을 받아 수행한 연구임

\section{References}

[1] S. Kim, G. Seok, and J. Bae, A Study of Low-Road Lamp for Fog Section. Korea Expressway Corporation Research Institute, 2013 Research report, 2013, pp. 1-36.

[2] G. Lee, "The Utilization of Visibility Information System for Frequently Fog Occurred Area on the Highway Using CCTV," J. of the Global It Research Institute of Korea university of transportation, vol. 6, no. 1, 2011, pp. 35-39.

[3] I. Kim, J. Yoo, and B. Kim, "A Monitoring Way and Installation System using Intelligent CCTV under the u-City Environment," J. of The Korea Institute of Electronic Communication Science, vol. 3, no. 4, 2008, pp. 295-303.

[4] K.-S. Park and Y.-T. Kim, "A Study for Video-based Vehicle Surveillance on Outdoor Road," J. of The Korea Institute of Electronic Communication Science, vol. 8, no. 11, 2013, pp. 1647-1653.

[5] C.-S. Kim, "A Study on the ITS integrated airport security system," J. of The Korea Institute of Electronic Communication Science, vol. 8, no. 2, 2013, pp. 339-344.

[6] T.-M. Kwon, An Atmospheric Visibility Measurements Using Video Cameras: Relative Visibility. Univ. of Minnesota Duluth, July 2004.

[7] B. Kim and G. Lee, "Decision of Optimal Objective Function for the Road Visibility
Measurement System," J. of the Global It Research Institute of Korea university of transportation, vol. 7, no. 1, 2012, pp. 21-25.

[8] B. Kim, I. Jang, and G. Lee, "Image based Realtime Road Visibility Measurement," J. of Korea society of Transportation. vol. 9, no. 4, 2011, pp. 125-138.

[9] J. H. Carrillo, S. E. Emert, D. E. Sherman, P. Herckes, and J. L. Collett, "An economical optical cloud/fog detector," Atmospheric Research, vol. 87 , no. 3, 2008, pp. 259-267.

$$
\text { 저자 소개 }
$$

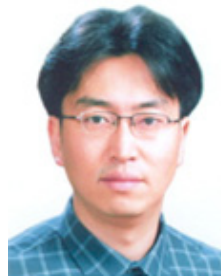

\section{이 광(Gwang Lee)}

1995년 조선대학교 컴퓨터공학과 학과 졸업(공학사) 1997년 조선대학교 대학원 컴퓨터 공학과 졸업(공학석사)

2000년 조선학교 대학원 컴퓨터공학과 졸업(공학박사) 1997년 현재 한국교통대학교 소프트웨어학과 교수 ※ 관심분야 : ITS, 시스템소프트웨어, 웹접근성

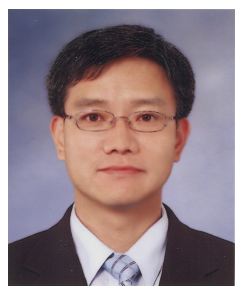

\section{김봉근(Bong-Kun Kim)}

1987년 수원대학교 전자계산학과 학과 졸업(공학사) 1991년 숭실대학교 대학원 전자계 산학학과 졸업(공학석사)

1997년 숭실대학교 대학원 전자계산학과 졸업(공학 박사)

1993년 현재 한국교통대학교 소프트웨어학과 교수 ※ 관심분야 : 컴퓨터비젼, 영상처리, ITS 